\title{
Using ICT in Distance Education: a Case
}

\author{
Herman Koppelman \\ Open University of the Netherlands \& \\ University of Twente \\ The Netherlands \\ herman.koppelman@ou.nl
}

\author{
Elisabeth M. A. G. van Dijk \\ University of Twente \\ The Netherlands
}

bvdiik@cs.utwente.n

\begin{abstract}
The paper describes a distance education course which uses ICT in a number of ways. In the first place the World Wide Web provides for part of the content. Next, the course is as far as possible available in a hyperstructure in electronic form. Finally, most of the necessary communication (for example between the students and between the students and their teacher) is supported by ICT. The paper describes extensively experiences with this course.
\end{abstract}

Keywords: distance education, web based learning, virtual teams, ICT.

\section{Introduction}

Distance education can profit in several ways from ICT. In this paper we describe a course that uses ICT-tools in the following ways:

- the World Wide Web provides for a substantial part of the content of the course;

- the course is, for a large part, available in electronic form for students

- communication between the students and between the students and other relevant persons is supported by ICT.

First we will describe in more detail the ways ICT is used in the course. Next we will describe a number of experiences we had with this course.

\section{Description of the course}

The course offers an introduction in Human-computer interaction (HCI). The main objective is that students learn to design the user interface of interactive systems (van der Veer, 1995).

Material published as part of this proceedings, either on-line or in print, is copyrighted by the author with permission granted to the publisher of Informing Science for this printing. Permission to make digital or paper copy of part or all of these works for personal or classroom use is granted without fee provided that the copies are not made or distributed for profit or commercial advantage AND that copies 1) bear this notice in full and 2) give the full citation on the first page. It is permissible to abstract these works so long as credit is given. To copy in all other cases or to republish or to post on a server or to redistribute to lists requires specific permission from the author.
The course has been developed in a Dutch collaboration project by the Open University of the Netherlands, the Technical University of Delft, the Technical University of Eindhoven and the University of Twente.

In this section we will describe the way ICT is used in this course.

\section{Content from sources on the WWW}

The courses of the Open University in the Netherlands are meant to be studied with only limited support from teachers. As a consequence the courses have to be very extensive and detailed (usually they have 500 or more pages for a study load of 120 hours). It takes a lot of time and money to develop such courses, they are not flexible, and for these reasons one is reluctant to revise them.

In the HCI course we had another approach and tried to use as much existing material as possible, preferably material that was available on the web. To integrate the different materials we developed an appropriate structure for the course. Figure 1 shows a model of this structure. (This is only a model, the actual structure is much more complicated.). A crucial part of the course is a case that is partly elaborated. The goal of this case is to show how contributions of several disciplines fit into an integral, coherent design process. An important aspect of this case is that it gives references and hyperlinks to all kinds of sources: preferably to websites, but also to a Reader we composed, containing relevant (parts of) publications that were not available on the WWW. 


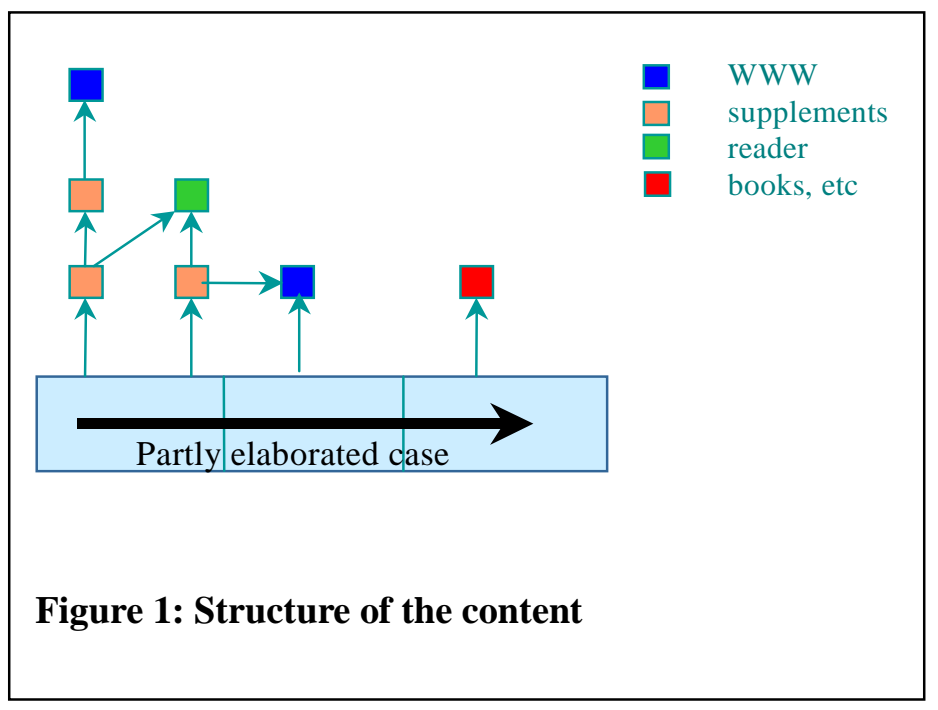

\section{Course available in electronic form}

As can be seen from figure 1 the course has, in a very natural way, a hyperstructure. For this reason the course is offered to the students as a hypertext in electronic form. Only the reader, which contains relevant papers and chapters of books, is not electronically available for copyright reasons.

\section{ICT to support communication}

The course is used in different situations. We focus on the way the Open University uses it: with team projects assigned to virtual teams. Teams of about four students are provided with the course materials and with a detailed assignment, which describes an interactive system they have to design for a 'client' (Koppelman, 2000). It is up to the students to divide the different tasks.

In this setting a lot of communication is needed: communication between the students mutually, between the students and the teachers and between the students and their 'client'. ICT is used to support these communications and in some cases even to make these communications possible.

When we chose tools, we had to reckon with the limited facilities of our students. As they study at home, they usually only have a slow connection to Internet at their disposal.

\section{Communication between the students}

Communication between the students can take place in several ways. We distinguish between synchronous and asynchronous communication. Synchronous communication can be done by:
- telephone, chatting and NetMeeting (Microsoft, http://www.microsoft.com/windows/netmeeting/s sessions: all the students have Internet at their disposal

- audio conferencing: every team is allowed to have a free audio conference once a week, for a maximum duration of one hour; the audio conferencing is supported by the Open University

- face-to-face meetings

Asynchronous communication can take place by:

- e-mail

- tools with a shared workspace; we used eRoom (Instinctive Technology, http://www.instinctive.com/html/eroom.htm, , BSCW (Basic Support for Cooperative Work, http://bscw.gmd.de and a closed discussion group.

\section{Communication between students and their teacher}

Face-to-face communication is hardly possible, because of the travel time. So, the teacher had to communicate with the students in other ways.

A number of instances of various methods of synchronous and asynchronous communication between the students and the teacher is planned ahead.

Asynchronous communication can take place by

- e-mail

- a shared workspace.

The students have to deliver a number of products at different moments. They can deliver these products by submitting them to a subfolder of the shared workspace. The teachers use the same subfolder for giving feedback to the students about the deliverables.

Moreover, there should be synchronous communication between the students and the teachers. The students should communicate at least once a week with the teacher, and it is up to them to choose the way of communication. They can decide themselves which members of the team should be involved. Possibilities are:

- (bilateral) telephone calls between one of the students and the teacher

- NetMeeting sessions between several students and the teacher

- audio conferencing between several students and the teacher. 


\section{ICT in Distance Education}

\section{Communication between the students and their 'client'}

The starting point for this communication is a videorecording of an interview with the client. This interview is available in MPEG format on a CD-rom. In this interview the client tells about his problem, gives some ideas about possible solutions and asks the group to elaborate these. Of course additional communication is needed. It is up to the teams and the client to choose ways for this communication. Possibilities are:

- e-mail and telephone

- NetMeeting sessions and audio conferencing

- face-to-face meetings

\section{Experiences with the Course}

In this section we will describe the experiences we had with the HCI course.

\section{The content of the course}

Developing the course took much less effort than usually is the case with courses for the Open University. We found a lot of sources on the WWW which could be used as content of the course.

The course has been used and is used by different universities in different contexts, with different study load for students, ranging from 40 hours to 120 hours. The course has been used within the setting of project education, but also in more traditional settings. It proved that the course can be easily adapted.

Most of the students of the Open University were positive about the content of the course. Although they are used to carefully constructed, closed courses, they had no problems with the more open approach this course offered.

A few of the strong points they mentioned in evaluations of the course are:

- This is an innovative course

- The problem is open

- The course is instructive

- The course offers an interesting combination of theory and practice.

The general impression is positive, but also a number of weak points are mentioned:

- It takes a lot of time

- Searching and printing web pages is boring and expensive.

\section{Course available in electronic form}

If the students had to study written materials, they read the text on paper, and not the text on the screen. The electronical version of the course has only been used by some students, mainly to find references easily. Some students said it was a problem that the different materials were not available in one medium.

\section{Communication}

\section{Communication between students}

We feel that bonding between the students is very important. So we organized a face-to-face meeting at the start of the project. After this kick-off meeting a lot of communication took place between the students.

There was a lot of synchronous communication between the students, mainly by way of audio conferencing and face-to-face meetings. All of the teams said that synchronous communication is indispensable in team projects. The teams usually had meetings (virtual or face-to-face) once a week. Roughly speaking, the ratio of virtual meetings and face-to-face meetings depended on the average travel time. If all of the students of a team lived near each other, usually the team had a face-to-face meeting once a week, and the team did not use other ways of synchronous communication. If they had to travel about 1 or 1.5 hours, they usually arranged face-to-face meetings and virtual meetings alternately. Teams who were not able to organize faceto-face meetings because the distances between them were too large, organized only audio conferences.

Some teams experimented with NetMeeting and tools for chatting. These teams complained that interesting features of NetMeeting (like application sharing) were too slow, and they stopped using it after two or three attempts. Another problem was that when you share NetMeeting with four participants the quality of the audio is very poor. Only one positive remark was made: afterwards you always have a report of a NetMeeting session.

Most of the teams used the shared workspace for asynchronous communication. Initially the groups were offered discussion groups as a shared workspace. The teams who used it extensively, complained that they could not edit or structure this workspace and that there was no version control. The teams were more enthousiastic about eRoom and BSCW.

Some of the teams only used e-mail, usually because using the shared workspace was slow or laborious or because 
some of the members of the team had problems accessing it.

Most students were positive about the team projects. Many students stressed that they want to have some training in collaboration. Some students who prefer to study alone were negative about team projects from the start ('communicating takes a lot of time, 'I cannot plan my own time', etc).

\section{Communication between the students and the teacher}

Using a subfolder of the shared workspace for submitting deliverables proved to be efficient and effective. What we did learn was that you should ask the groups to structure this subfolder, to prevent it from becoming disorderly.

Synchronous communications happened mainly by bilateral telephone calls. Sometimes the teacher shared an audio conference. This seems especially sensible if the teacher feels it is appropriate to motivate a team.

\section{Communication between the students and the client}

Usually the teams were not very eager to communicate with the client. Rather, most of the teams behaved somewhat defensively towards him or her.

Usually they only submitted to the client those products that they were obliged to according to the assignment. All of the communication happened by e-mail. The teams did not try to have synchronous communication.

In future classes we will invite the client for the kick-off meeting. We hope that by having a face-to-face meeting the teams will have more communication with the client and will be less reluctant to involve him or her in the project.

\section{Conclusions}

By using existing materials from the WWW and from other sources we could develop a flexible and cheap course. The course proved to be usable in different educational settings.

Although the course has a very natural hyperstructure, the on line version of the course was hardly used by the students.

Synchronous communication is indispensable for the team projects of this course. It seems the students prefer to have face-to-face meetings. If the students feel the distances between them are too large, they have a mix of face-to-face meetings and virtual meetings or they have only virtual meetings.

Simple tools for (synchronous and asynchronous) communication suffice, but more sophisticated tools have a stimulating effect.

\section{References}

Koppelman, H., Dijk, E.M.A.G. van, Mast, C.A.P.G. van der, Veer, G.C. van der (2000). Team Projects in Distance Education: a Case in HCI Design. SIGCSE Bulletin, 32 (3), 97-100.

Veer, G.C. van der, Vliet, J.C. van, Lenting, B.F. (1995). Designing complex systems - a structured activity, Proceedings DIS'95, 207217.

\section{Biographies}

Herman Koppelman is a member of the department of Computer Science of the Open University in the Netherlands. He is also educational consultant for the department of Computer Science of the University of Twente

Betsy van Dijk is an assistant professor in human-computer interaction of the department of Computer Science of the University of Twente. 